\title{
(6) OPEN ACCESS \\ Changes in intraocular pressure after intravitreal fluocinolone acetonide (ILUVIEN): real-world experience in three European countries
}

\author{
Usha Chakravarthy, ${ }^{1}$ Simon R Taylor, ${ }^{2}$ Frank H Johannes Koch, ${ }^{3}$ \\ João Paulo Castro de Sousa, ${ }^{4}$ Clare Bailey, ${ }^{5}$ On behalf of the ILUVIEN Registry Safety \\ Study (IRISS) Investigators Group
}

\begin{abstract}
- Additional material is published online only. To view please visit the journal online (http://dx.doi.org/10.1136/ bjophthalmol-2018-312284).

${ }^{1}$ Centre for Public Health, Queen's University Belfast, Belfast, United Kingdom ${ }^{2}$ Ophthalmology Department, Royal Surrey County Hospital, Guildford, UK

${ }^{3}$ Clinic of Ophthalmology, Goethe University, Frankfurt am Main, Germany

${ }^{4}$ Ophthalmology Department, Leiria Hospital Center, Leiria, Portugal

${ }^{5}$ Bristol Eye Hospital, Bristol, UK
\end{abstract}

\section{Correspondence to}

Professor Usha Chakravarthy, Queen's University Belfast, University Road, Belfast, BT7 $1 \mathrm{NN}$, United Kingdom; u. chakravarthy@qub.ac.uk

Received 29 March 2018 Revised 3 August 2018 Accepted 21 August 2018 Published Online First 21 September 2018

\begin{abstract}
Aims The ILUVIEN Registry Safety Study is an ongoing, multicentre, open-label, observational study collecting real-world data on the safety and effectiveness of the $0.2 \mu \mathrm{g} /$ day fluocinolone acetonide (FAc) implant in patients treated according to the European label requirements.

Methods Patients included in this analysis were treated for the licensed indication of chronic diabetic macular oedema (cDMO; that is, DMO that persists or recurs despite treatment). Data presented in the current analysis were collected from patient records up to 6 March 2017. Visual acuity (VA) data, including mean change in VA over time and at last observation, intraocular pressure (IOP) over the course of the study, IOP events, use of IOP-lowering therapy and cup:disc ratio were analysed. Information on additional DMO treatments post-FAc implant was also captured.
\end{abstract}

Results Five hundred and sixty-three patients (593 eyes) were enrolled on the study. Mean IOP for the overall population remained within the normal range throughout follow-up and $76.7 \%$ of patients did not require IOP-lowering therapy following treatment with the FAc implant. Sixty-nine per cent of eyes did not require additional DMO treatments. Mean VA in the overall population increased from 51.9 letters at baseline to 55.6 letters at month 12 , with a significant increase of 2.9 letters at last observation. Patients with short-term CDMO experienced greater VA gains than those with long-term cDMO.

Conclusions The results of this analysis are comparable with those of other studies, including the Fluocinolone Acetate for Macular Edema study. The study reinforces the good safety and effectiveness profile of FAc, and demonstrates the benefit of early FAc treatment.

\section{INTRODUCTION}

Diabetic macular oedema (DMO) is a chronic, vision-limiting condition and is the most common cause of vision impairment in patients with diabetes. ${ }^{1}$ DMO is estimated to affect 21 million individuals worldwide, ${ }^{2}$ with the number of individuals with DMO expected to increase in the coming years due to the general ageing of the population, the increasing prevalence of diabetes and the increasing life expectancy of patients with diabetes.
Anti-vascular endothelial growth factor (antiVEGF) therapies are widely accepted as the current standard of care in patients with DMO. ${ }^{3}$ Nonetheless, recent evidence indicates that the pathogenesis of DMO is multifactorial, involving VEGF and also upregulation of multiple inflammatory cytokines, particularly in long-standing DMO, suggesting that inflammation plays an important role with increasing chronicity. ${ }^{4-6}$ Consequently, blocking VEGF alone is unlikely to be sufficiently effective, particularly in long-standing DMO. In the RIDE and RISE trials, it was observed that only $5.7 \%$ of patients initially treated with sham injections for 2 years before switching to ranibizumab experienced a $\geq 3$-step improvement in best-corrected visual acuity (VA) compared with $17.7 \%$ and $18.8 \%$ of those treated from study inception with $0.3 \mathrm{mg}$ ranibizumab and $0.5 \mathrm{mg}$ ranibizumab, respectively. Additionally, a greater proportion of patients in the sham/cross-over group experienced a worsening in VA at month 36 compared with other treatment groups. ${ }^{7}$

Previous trials of intravitreal corticosteroids for the treatment of DMO have shown that they reduce the levels of inflammatory cytokines, including VEGF, in the vitreous ${ }^{8}$; they therefore represent an alternative therapeutic option for patients with longer-duration DMO. While corticosteroids have the potential to cause side effects that limit their use, including cataract formation and increased intraocular pressure (IOP), ${ }^{9}$ clinical trials have shown significant benefits in terms of VA and duration of action. The slow-release, non-bioerodible, fluocinolone acetonide (FAc) intravitreal implant (ILUVIEN; Alimera Sciences, Aldershot, UK) releases low-dose FAc $(0.2 \mu \mathrm{g} /$ day $)$ into the vitreous of the eye for up to 36 months. The implant is approved in Europe for the treatment of vision impairment associated with chronic DMO (cDMO) considered insufficiently responsive to available therapies; approval was based on evidence from the Fluocinolone Acetate for Macular Edema (FAME) studies. ${ }^{9} 10$ Subsequent safety and real-world evidence studies are ongoing. ${ }^{11}$

The ILUVIEN Registry Safety Study (IRISS; NCT01998412) post-regulatory approval study was designed as part of a regulatory requirement within European countries where the FAc implant is currently marketed. Real-world safety and tolerability data-including incidence and management 
of IOP rise, and the change in VA- and functional outcomes were acquired from patients receiving the $0.2 \mu \mathrm{g} /$ day FAc implant. ${ }^{12}$

\section{METHODS}

IRISS is a European, multicentre, open-label, observational registry study of patients treated with the FAc implant for any reason. The study is registered at ClinicalTrials.gov (NCT01998412). The observation phase is ongoing, with a planned duration of follow-up of 5 years. There are 31 participating sites in the UK, 11 in Germany and 5 in Portugal. The IRISS study was originally designed as a prospective study; therefore, collection of data prior to administration of the $0.2 \mu \mathrm{g} /$ day FAc implant was not included in the study protocol.

Data were collected from patient records from each participating site with the first patient enrolled on 10 April 2014. Ethics committee approval was obtained in all countries prior to study inception. The present analysis was conducted on data collected up to 6 March 2017.

VA outcomes were VA stability (defined as a change of \pm 4 ETDRS letters from baseline) or improvement (defined as an increase of $\geq 5$ ETDRS letters from baseline), mean change in VA at last observation and mean change in VA over time, and percentage of patients achieving driving vision. The area under the VA-versus-time curve (AUC) ${ }^{13}$ was used to compare VA gain (ETDRS letter gains per day) over the course of the study in phakic and pseudophakic eyes. This AUC analysis was employed to overcome the effect of any short-term fluctuations in VA resulting from cataract formation or surgery.

The FAME studies introduced the concept of $\mathrm{cDMO}$, where an enhanced treatment effect compared with the control group was observed in patients with duration of DMO greater than the median for the population; this was a result of poorer response to the standard-of-care therapies administered in this control subgroup. Patients in the IRISS population received the FAc implant for the EU-licensed indication of cDMO considered insufficiently responsive to available therapies and were treated with the FAc implant as a second-line or even third-line treatment. The IRISS population was grouped by history of longterm ( $>3$ years) and short-term ( $\leq 3$ years) duration of cDMO. The outcomes in these groups were compared to assess the effect of the FAc implant.

IOP events investigated were change in IOP over the course of the study, IOP increase, absolute IOP of $>21 \mathrm{~mm} \mathrm{Hg},>25 \mathrm{~mm} \mathrm{Hg}$ and $>30 \mathrm{~mm} \mathrm{Hg}$, percentage of patients receiving treatment-emergent IOP medication and percentage of patients requiring trabeculoplasty or trabeculectomy. Cup:disc ratio (CDR) and adverse events (AEs) were also analysed.

Details of any additional therapies re-initiated following treatment with the FAc implant were captured on the casereport form. The mean time to additional treatment re-initiation was calculated using a Kaplan-Meier analysis. For each eye, the number of days between the date of initial FAc treatment and the date of re-initiated DMO treatment was calculated. If at the time of the data cut-off no additional treatment post-FAc had been administered, then a value equal to the total number of days' follow-up was used for these eyes. Kaplan-Meier estimates were then calculated based on data from all eyes.

Outcomes were compared with those of the CDMO subgroup of the FAME study at a similar time point, ${ }^{9}{ }^{10}$ and descriptive statistical analyses were performed.
Table 1 Patient demographics and baseline characteristics for IRISS and FAME $^{23}$

\begin{tabular}{lll}
\hline Parameters & IRISS & FAME* \\
\hline No of patients (eyes) & $563(593)$ & 209 \\
\hline Mean age, years \pm SD & $67.5 \pm 10.7$ & $63.7 \pm 8.9$ \\
\hline Gender (\% male:female) & $56.3: 43.7$ & $57.4: 42.6$ \\
\hline Lens status (\% pseudophakic:phakic:aphakic) & $82.6: 16.4: 0.7 \dagger$ & $45.5: 54.5: 0$ \\
\hline Mean IOP, mm Hg \pm SD & $15.6 \pm 3.3 \ddagger$ & $15.0 \pm 2.9$ \\
\hline Mean duration of DMO, years \pm SD & $4.5 \pm 3.9$ & $5.1 \pm 3.1$ \\
\hline Mean duration of follow-up, days (range) & $471.2(1-1269)$ & $998.5(36-1236)$ \\
\hline FAc implant placement (\% unilateral:bilateral) & $82.8: 17.2$ & $100: 0$ \\
\hline FAc implants received per eye (\% 1 implant: & $99.0: 0.8: 0.2$ & $76.1: 18.7: 5.3$ \\
2 implants: $\geq 3$ implants) & & \\
\hline
\end{tabular}

* Patients with CDMO who received the $0.2 \mu \mathrm{g} /$ day FAc implant.

t0.3\% of patients had no lens status data at baseline.

‡Data are for 351 eyes for which IOP data were available at baseline.

FAME, Fluocinolone Acetonide for Macular Edema; FAc, fluocinolone Acetonide; IOP, intraocular pressure; IRISS, ILUVIEN Registry Safety Study; CDMO, chronic diabetic macular oedema.

\section{RESULTS}

\section{Patient disposition and baseline characteristics}

\section{Study population}

A total of 593 eyes of 563 patients with a diagnosis of DMO were enrolled on the study. All patients had been identified by their treating physician as demonstrating an insufficient response to prior DMO therapy and were therefore considered to have cDMO. The comparison between the baseline demographics of IRISS and the FAME study is shown in table 1. The majority of patients in the IRISS registry $(82.8 \%)$ had unilateral implantation with the FAc implant and $99.0 \%$ received only one implant during the follow-up period (table 1). The IRISS study population had a broader range of DMO duration at baseline compared with the FAME study. In addition, 5.2\% of patients in IRISS had an IOP $>21 \mathrm{~mm} \mathrm{Hg}$ at baseline; this was an exclusion criterion in the FAME study.

\section{IOP outcomes}

The mean IOP in the entire IRISS population remained in the normal range throughout the 24-month follow-up period (online supplementary figure S1), and this was unaffected by subgroup classification by lens status (phakic or pseudophakic) and cDMO duration (short term vs long term).

IOP outcomes were similar to those observed in the FAME study; mean IOP rise at month 24 in both the FAME study (Alimera, data on file) and the IRISS overall study population was $1.9 \mathrm{~mm} \mathrm{Hg}$. IOP changes for the individual subgroups were $2.6 \mathrm{~mm} \mathrm{Hg}$ for the long-term cDMO subgroup, $1.8 \mathrm{~mm} \mathrm{Hg}$ for the short-term cDMO subgroup, $1.9 \mathrm{~mm} \mathrm{Hg}$ for the pseudophakic subgroup and $2.2 \mathrm{~mm} \mathrm{Hg}$ for the phakic subgroup. The incidence of IOP elevation was consistent with that reported for patients with $\mathrm{CDMO}$ in the FAME study (online supplementary table S1) and the majority of patients $(76.7 \%)$ did not require initiation of IOP-lowering therapy following treatment with the FAc implant (table 2).

\section{Cup:disc ratio}

There were no clinically significant changes in CDR from baseline (0.36) to month $24(0.46)$ in eyes for which CDR data were available $(\mathrm{N}=229)$. No tests of statistical significance were performed due to the post hoc nature of the study. 


\begin{tabular}{|c|c|}
\hline & $\begin{array}{l}\text { IRISS } \\
(n=593)\end{array}$ \\
\hline \multicolumn{2}{|l|}{ IOP events } \\
\hline \multicolumn{2}{|l|}{ IOP post-FAc, n (\%) } \\
\hline$>21 \mathrm{~mm} \mathrm{Hg}$ & $199(33.6)$ \\
\hline$>25 \mathrm{~mm} \mathrm{Hg}$ & $113(19.1)$ \\
\hline$>30 \mathrm{~mm} \mathrm{Hg}$ & $49(8.3)$ \\
\hline $\mathrm{CDR}$, mean $\pm \mathrm{SD}$ & $0.46 \pm 0.195^{*}$ \\
\hline \multicolumn{2}{|l|}{ IOP treatments } \\
\hline Trabeculoplasty, n (\%) & $2(0.3)$ \\
\hline Trabeculectomy, n (\%) & $7(1.2)$ \\
\hline Incisional IOP-lowering surgery, $\mathrm{n}(\%)$ & $5(0.8)$ \\
\hline \multicolumn{2}{|l|}{ No of treatment-emergent IOP-lowering medicationst, $\mathrm{n}(\%)$} \\
\hline Any & $138(23.3)$ \\
\hline 1 & $62(44.9)$ \\
\hline 2 & $30(21.7)$ \\
\hline 3 & $21(15.2)$ \\
\hline$>3$ & $25(18.2)$ \\
\hline $\begin{array}{l}\text { Time to first IOP-lowering medication post-FAc } \neq \text {, days, } \\
\text { mean } \pm \text { SD }\end{array}$ & $244.2 \pm 197.9$ \\
\hline
\end{tabular}

* Month 24 CDR data are available for 32 patients. †IOP-lowering medication initiated after $0.2 \mu \mathrm{g} / \mathrm{day}$ FAc implant administration. $\neq$ Data were available for 138 patients ( $23.3 \%$ of the study population). CDR, cup:disc ratio; FAc, fluocinolone Acetonide; IOP, intraocular pressure; IRISS, ILUVIEN Registry Safety Study.

\section{AEs and additional treatments}

Within 360 days of FAc implant insertion, 170 eyes experienced 234 ocular AEs. The most common ocular AE was subconjunctival haemorrhage (21 eyes), followed by ocular hypertension (19 eyes) and posterior capsule opacification (12 eyes). In a single patient, migration of the implant into the anterior chamber led to study discontinuation.

\section{Additional DMO treatments}

Of the treated eyes, $69.0 \%$ did not require additional treatments during the follow-up period of this study. Additional treatments that were initiated after the first FAc implantation included thermal laser $(9.6 \%$ of eyes), intravitreal anti-VEGF injection (22.4\% of eyes), intravitreal steroid injection (6.6\% of eyes) and retreatment with the FAc implant (1.0\% of eyes) (online supplementary table S2). The mean time to additional treatment was $356.1 \pm 274.8$ days.

\section{Prior treatments}

Few eyes were treatment-naïve (1.0\%); previou s treatments included thermal laser, intravitreal anti-VEGF or ocular steroid injections (online supplementary table S3).

\section{VA distribution at baseline}

The mean baseline VA was $51.9 \pm 18.2$ letters. Baseline VA distribution (online supplementary figure S2) reveals a broader VA range compared with the FAME study population.

\section{VA outcomes \\ Overall population}

Mean VA increased from 51.9 ETDRS letters at baseline to 55.6 letters at month 12. A mean gain of 1.8-2.9 letters was sustained up to month 24 and was +2.9 letters at last observation $(\mathrm{p}<0.001)$. The percentage of patients with stable or improved VA over 24 months was similar to the FAME study (figure 1).

\section{Lens status}

There was no significant difference in the AUC of the two subgroups ( $\mathrm{p}=0.584$; figure 2). Both phakic and pseudophakic

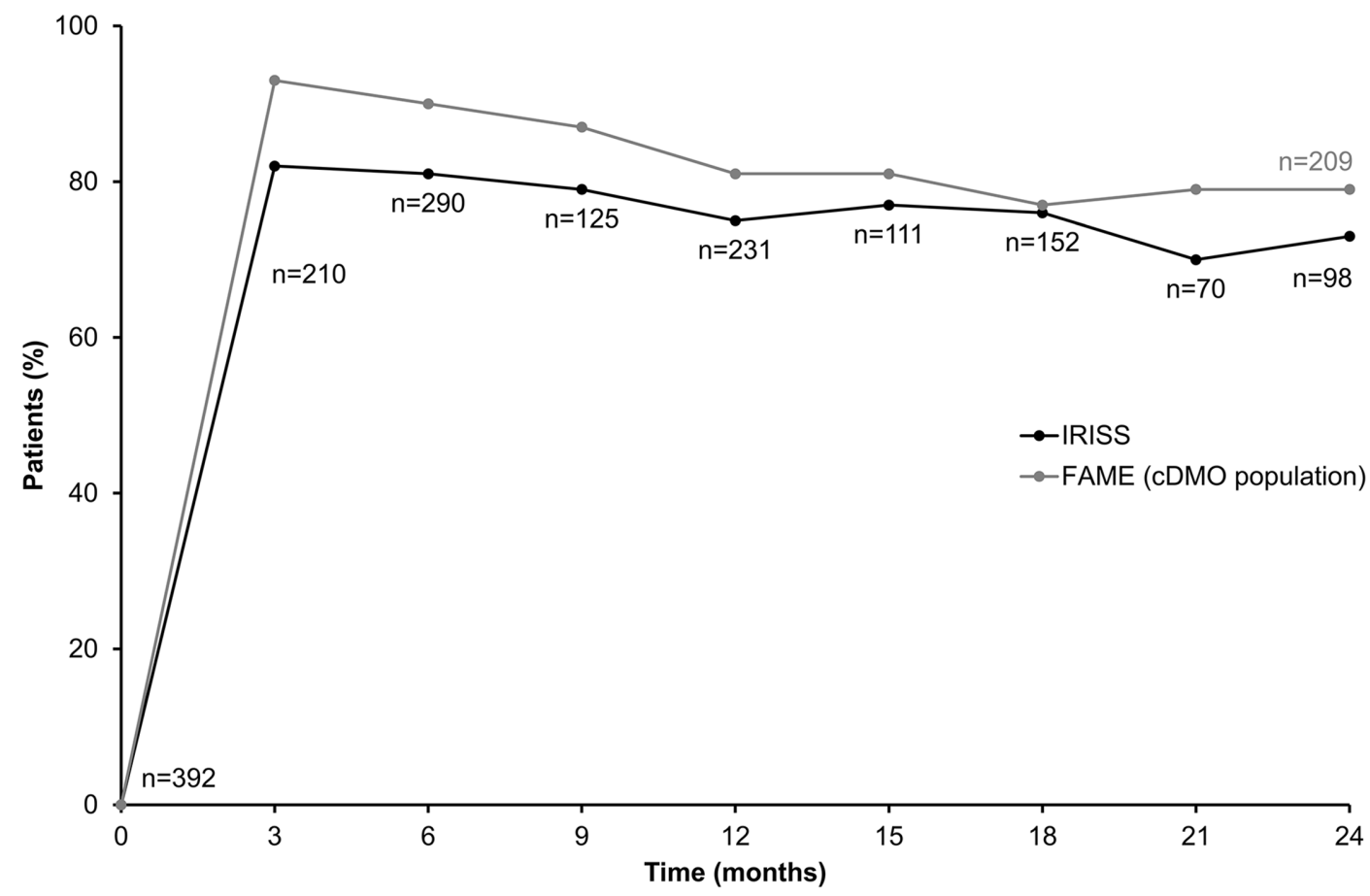

Figure 1 VA stability or improvement in IRISS compared with FAME. CDMO, chronic diabetic macular oedema; FAME, Fluocinolone Acetate for Macular Edema; IRISS, ILUVIEN Registry Safety Study; VA, visual acuity. 


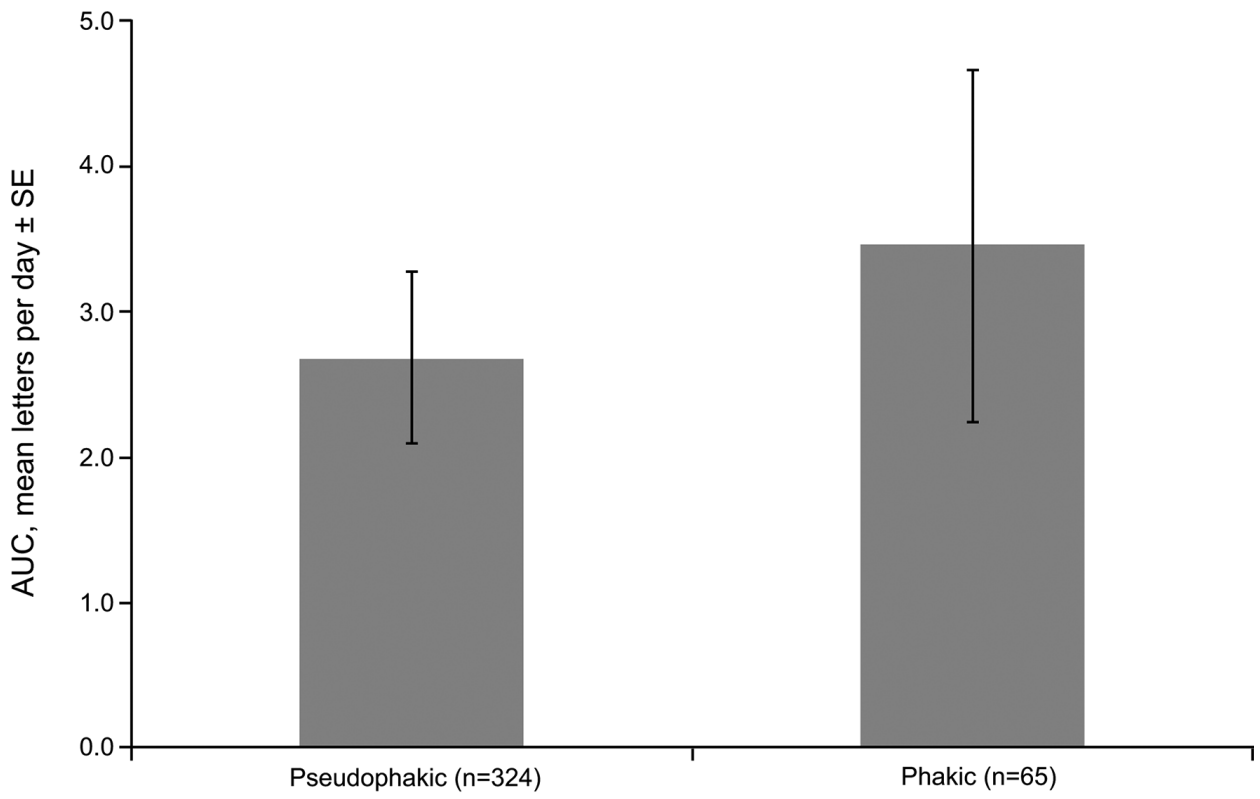

Lens status

Figure 2 AUC for phakic and pseudophakic subgroups. AUC, area under the visual acuity-versus-time curve.

subgroups experienced significant VA gains at last observation (table 3).

\section{Duration of CDMO}

Both the short-term and long-term cDMO subgroups experienced significant increases in VA at 3 months $(p<0.001)$, and these gains were sustained through 24 months' follow-up in both subgroups (figure 3). In phakic eyes, mean increases were similar in the shortterm and long-term cDMO subgroups. In pseudophakic eyes, a differential increase in gain was observed with the short-term cDMO group gaining on average 8.2 letters compared with 1.7 letters in the long-term cDMO group $(\mathrm{p}<0.001)$ (table 3$)$. The short-term cDMO subgroup had received treatment for DMO (focal or grid laser, panretinal photocoagulation or, most frequently, ranibizumab) more recently than the long-term cDMO subgroup (7.08 months vs 9.96 months, respectively; online supplementary tables S4 and S5).

\section{Achievement of driving vision}

A functional measure of vision improvement is the achievement of driving vision ( $\geq 6 / 12$ Snellen fraction, approximately 70 ETDRS letters). At baseline, $19.4 \%$ had a VA in the study eye that was $\geq 6 / 12$ Snellen. This increased to $27 \%$ at month 3 and reached a maximum of $32 \%$ at month 12 (online supplementary figure S3). Overall, there was a tendency for more patients in

Table 3 Mean change in VA at last observation by subgroup

\begin{tabular}{lllllll}
\hline & \multicolumn{2}{l}{ Pseudophakic } & & Phakic \\
\cline { 2 - 3 } \cline { 5 - 6 } cDMO duration & $\begin{array}{l}\text { Long } \\
\text { term }\end{array}$ & $\begin{array}{l}\text { Short } \\
\text { term }\end{array}$ & & $\begin{array}{l}\text { Long } \\
\text { term }\end{array}$ & $\begin{array}{l}\text { Short } \\
\text { term }\end{array}$ \\
\hline $\mathrm{N}$ (eyes) at baseline & 269 & 53 & & 45 & 17 \\
\hline Mean VA at baseline, ETDRS letters & 52.1 & 49.9 & & 52.2 & 49.8 \\
$\begin{array}{l}\text { Mean change in VA at last observation, } \\
\text { ETDRS letters } \pm S E\end{array}$ & $1.7 \pm 1.0$ & $8.2 \pm 2.3$ & & $4.9 \pm 2.6$ & $5.0 \pm 2.3$ \\
P values & 0.084 & $<0.001$ & & 0.068 & 0.043 \\
\hline
\end{tabular}

CDMO, chronic diabetic macular oedema; ETDRS, Early Treatment Diabetic Retinopathy Study; VA, visual acuity. the shorter DMO duration subgroup to achieve driving vision (online supplementary figure S3).

\section{DISCUSSION}

The results of this real-world analysis of patients with cDMO confirm the safety profile of the $0.2 \mu \mathrm{g} /$ day FAc implant that was established by the FAMEstudy, despite the differences in the patient population. ${ }^{9}{ }^{10}$

We observed that the majority of patients treated with the FAc implant did not require IOP-lowering therapy and the low proportion of eyes experiencing IOP rise in the present study is consistent with the known side-effect profile for intravitreal steroids in the FAME and other studies. ${ }^{914-18}$ The proportions of patients with a recorded IOP $>30 \mathrm{~mm} \mathrm{Hg}$ at any visit, IOP-lowering surgery and treatment-emergent IOP-lowering medication were also similar to that observed in FAME. These outcomes were also comparable with that reported in the Medisoft audit, ${ }^{11}$ with one notable exception. In IRISS, $23.3 \%$ of patients required IOP-lowering medication compared with $13.9 \%$ of patients in the Medisoft audit. The low proportion in the latter likely reflects clinical practice of the UK, as all Medisoft sites were UK-based.

There was no clinically significant change in mean CDR following FAc implant administration, which supports the FAME data. ${ }^{19}$ In addition, the low average increase in IOP over the follow-up period suggests that widening the treatment population to populations not included in the pivotal trial is unlikely to increase the risk of glaucoma.

The European licence requires that for FAc treatment, patients should have experienced a suboptimal response to prior DMO treatments, including anti-VEGF. Thus, patients who were entered into the IRISS database had persistent or recurrent DMO despite treatment. It is of note that, post-FAc implant administration, the majority of treated eyes (69\%) were not given any additional DMO treatments during the period of follow-up.

Overall stability or improved VA was seen in $81 \%$ of patients at 6 months and in $75 \%$ of patients at 12 months. This is comparable with the findings of the FAME study, even though patients in IRISS tended to have a broader range of DMO duration at 


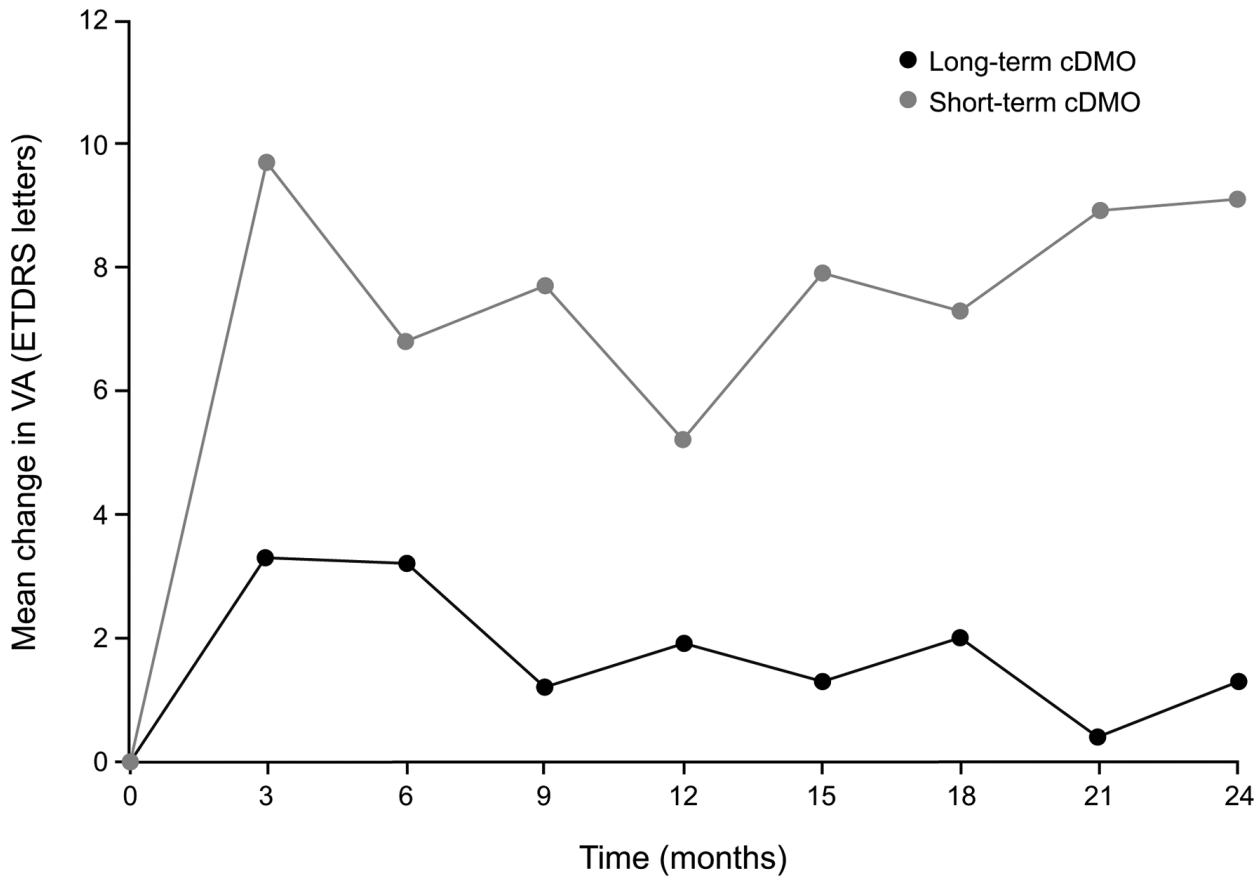

Figure 3 Mean change in VA over time by CDMO duration. CDMO, chronic diabetic macular oedema; VA, visual acuity.

baseline and had received more prior therapy compared with FAME.

Encouragingly, more than one quarter of patients at 6 months and 24 months attained vision that was $\geq 6 / 12$ in the treated eye; this is the legal minimum vision requirement for driving in the UK and therefore a meaningful functional measure of vision improvement.

The current findings are in line with the results of recent case reports and other studies of the FAc implant for the treatment of DMO in real-world settings. ${ }^{11}{ }^{20-22}$ Given that most patients had received prior therapy for DMO, this study highlights the potential additional effectiveness that can be gained by switching to the FAc implant in patients insufficiently responsive to other treatment options. Greater mean gains in VA were observed in eyes with short-term cDMO compared with longer-duration cDMO. When the duration since prior treatment (focal or grid laser, panretinal photocoagulation or ranibizumab) was analysed, it was found that patients with short-term cDMO had received treatment more recently than patients with long-term cDMO. These results indicate that switching to FAc as soon as an insufficient response to prior treatment is observed may be beneficial for functional outcomes.

Key strengths of this study are the large number of patients included, the diversity of the patient population in terms of baseline clinical characteristics and the fact that patients were treated with the FAc implant in real-world clinical settings.

As with other real-world studies, these data have limitations. VA was obtained in a real-world clinic setting, likely without correction for refractive error and rigorous testing to protocol. Although these factors enable translation of the study findings to routine clinical practice, comparisons with outcomes from clinical trials would be inappropriate. Also, IRISS differs from the clinical trials in that there was no restriction to cataract surgery or other treatments concomitant with FAc implant administration.

In conclusion, the results of this analysis of the real-world data collected in the IRISS study are broadly comparable with those of the FAME study and with data reported from the UK Medisoft database. This ongoing registry study further builds on similar real-world studies of the FAc implant by expanding the number of countries in which data are collected and by assessing both safety and effectiveness results. The data demonstrate a clear benefit of early treatment of cDMO with the FAc implant in terms of IOP and VA outcomes. The data from this study demonstrate the good safety profile and clinically meaningful effectiveness of the FAc implant, and provide evidence that it is a valuable therapeutic approach for patients with persistent or recurrent DMO insufficiently responsive to other treatment options.

Contributors All authors made substantial contributions to conception, design, analysis and interpretation of data and contributed to writing the article and approved the current version.

Funding This study was funded by Alimera Sciences. Medical writing assistance was provided by Helios Medical Communications, Alderley Edge, Cheshire, UK and funded by Alimera Sciences.

Competing interests UC is a speaker and advisory board member for Alimera Sciences, an advisory board member for Allergan, Bayer, Novartis and Roche, and has received grants from Bayer, Novartis and Roche. SRT reports financial relationships with GlaxoSmithKline and Novartis, and speaker honoraria, advisory boards and travel grants from Alimera Sciences, Allergan, Bayer, GlaxoSmithKline, Novartis and Santen. FHJK reports a commercial relationship with Alimera Sciences. JPCdS reports no conflicts of interest. CB reports financial support from Alcon, Alimera Sciences, Allergan, Bayer and Novartis.

\section{Patient consent Obtained.}

Ethics approval UK: HSC Research Ethics Committee 2 (14/NI/0002). Portugal: Comissão de Ética para a Saúde da AIBILI (N/A), CES IRL (N/A), CEIC (2014-EO-03), CES Hospital Vila Franca de Xira (N/A), CES Centro Hospitalar do Porto (2015.130 (117-DEFI/107-CES)), CES Centro Hospitalar de Leiria (N/A), CES Centro Hospitalar de Setúbal (0015/2016F), CES Centro Hospitalar de Lisboa Ocidental, EPE (N/A), Comissão de Ética da U. L. S. Matosinhos (36/CE/JAS). Germany: Ethik kommission Landesärztekammer Rheinland-Pfalz (837.501.13 (9186-F)), Ethik kommission Universitäts Klinikum Tubingen (088/2014B02), Ethik kommission Rheinische Friedrich-Wilhelms-Universität (044/14), Ethik kommission der ärztekammer Hamburg (N/A), Ethik kommission Universität Leipzig (N/A), Ethik kommission Universität Dusseldorf (4585), Ethik kommission der ärztekammer Berlin (N/A), Ethik kommission Heidelberg (S-058/2014).

Provenance and peer review Not commissioned; externally peer reviewed. Author note Trial locations: UK: Moorfields Eye Hospital, Queen's University Belfast, Gloucestershire Royal Hospital, Frimley Park Hospital, Heart of England 
NHS Foundation Trust, King's College Hospital, Royal Surrey County Hospital, Imperial College London, Central Manchester University Hospitals, Plymouth Hospitals, Sheffield Teaching Hospitals, Sandwell and West Birmingham Hospitals, University Hospitals Birmingham, James Paget University Hospitals, City Hospitals Sunderland, Wrightington Wigan and Leigh Eye Unit, University Hospitals Leicester, Leighton Hospital, East Kent University Hospital, Portsmouth Hospitals, Royal Free Hospital London, The Royal Wolverhampton NHS Trust, Calderdale Hospital, Aintree University Hospital, Bristol Eye Hospital, Hull East Yorkshire Hospital, Queen's Hospital, Maidstone Hospital, Royal Derby Hospital, Whipps Cross University Hospital, Norfolk and Norwich University Hospital; Germany: University Mainz, STZ Eyetrial, University of Bonn, Hamburg-Eppendorf, Eye Hospital Leipzig, Eye Centre Spreebogen, University of Heidelberg, Universitätsklinikum Carl Gustav Carus, Universitätsklinikum des Saarlandes; Portugal: AIBILI, Instituto de Retina e Diabetes Ocular de Lisboa, Santo Antonio, Hospital Leiria, Unidade Local de Saude de Matosinhos.

Open access This is an open access article distributed in accordance with the Creative Commons Attribution Non Commercial (CC BY-NC 4.0) license, which permits others to distribute, remix, adapt, build upon this work non-commercially, and license their derivative works on different terms, provided the original work is properly cited, appropriate credit is given, any changes made indicated, and the use is non-commercial. See: http://creativecommons.org/licenses/by-nc/4.0/

\section{REFERENCES}

1 Klein R, Klein BEK, Moss SE, et al. The Wisconsin epidemiologic study of diabetic retinopathy XV. Ophthalmology 1995;102:7-16.

2 Yau JW, Rogers SL, Kawasaki R, et al. Global prevalence and major risk factors of diabetic retinopathy. Diabetes Care 2012;35:556-64.

3 Boyer DS, Hopkins JJ, Sorof J, et al. Anti-vascular endothelial growth factor therapy for diabetic macular edema. Ther Adv Endocrinol Metab 2013;4:151-69.

4 Dong N, Xu B, Wang B, et al. Study of 27 aqueous humor cytokines in patients with type 2 diabetes with or without retinopathy. Mol Vis 2013;19:1734-46.

5 Dong N, Xu B, Chu L, et al. Study of 27 aqueous humor cytokines in type 2 diabetic patients with or without macular edema. PLoS One 2015;10:e0125329.

6 Romero-Aroca P, Baget-Bernaldiz M, Pareja-Rios A, et al. Diabetic macular edema pathophysiology: vasogenic versus inflammatory. J Diabetes Res 2016;2016:1-17.

7 Boyer DS, Nguyen QD, Brown DM, et al. Outcomes with as-needed ranibizumab after initial monthly therapy: long-term outcomes of the phase III RIDE and RISE Trials. Ophthalmology 2015;122:2504-13.

8 Sohn HJ, Han DH, Kim IT, et al. Changes in aqueous concentrations of various cytokines after intravitreal triamcinolone versus bevacizumab for diabetic macular edema. Am J Ophthalmol 2011;152:686-94.

9 Campochiaro PA, Brown DM, Pearson A, et al. Sustained delivery fluocinolone acetonide vitreous inserts provide benefit for at least 3 years in patients with diabetic macular edema. Ophthalmology 2012;119:2125-32.
10 Campochiaro PA, Brown DM, Pearson A, et al. Long-term benefit of sustained-delivery fluocinolone acetonide vitreous inserts for diabetic macular edema. Ophthalmology 2011;118:626-35.

11 Bailey C, Chakravarthy U, Lotery A, et al. Real-world experience with $0.2 \mu \mathrm{g} /$ day fluocinolone acetonide intravitreal implant (ILUVIEN) in the United Kingdom. Eye 2017;31:1707-15.

12 Medicines and Healthcare Products Regulatory Agency. 2018. Iluvien 190 micrograms intravitreal implant in applicator. Public Assessment Report. PL 41472/0001; UK/H/3011/001/E01. http://www.mhra.gov.uk/home/groups/par/documents/ websiteresources/con171936.pdf.

13 Gross JG, Glassman AR, Jampol LM, et al. Panretinal photocoagulation vs intravitreous ranibizumab for proliferative diabetic retinopathy: a randomized clinical trial. JAMA 2015;314:2137-46.

14 Boyer DS, Yoon YH, Belfort R, et al. Three-year, randomized, sham-controlled trial of dexamethasone intravitreal implant in patients with diabetic macular edema. Ophthalmology 2014;121:1904-14.

15 Daruich A, Matet A, Behar-Cohen F. Sustained-release steroids for the treatment of diabetic macular edema. Curr Diab Rep 2015;15:99.

16 Diabetic Retinopathy Clinical Research Network. A randomized trial comparing intravitreal triamcinolone acetonide and focal/grid photocoagulation for diabetic macular edema. Ophthalmology 2008;115:1447-59.

17 Diabetic Retinopathy Clinical Research Network (DRCR.net), Beck RW, Edwards $A R$, et al. Three-year follow-up of a randomized trial comparing focal/grid photocoagulation and intravitreal triamcinolone for diabetic macular edema. Arch Ophthalmol 2009;127:245-51.

18 Parrish RK, Campochiaro PA, Pearson PA, et al. Characterization of intraocular pressure increases and management strategies following treatment with fluocinolone acetonide intravitreal implants in the FAME trials. Ophthalmic Surg Lasers Imaging Retina 2016;47:426-35.

19 Parrish RK, Traverso CE, Green K, et al. Quantitative assessment of optic nerve changes in patients with diabetic macular edema treated with fluocinolone acetonide vitreous implants. Ophthalmic Surg Lasers Imaging Retina 2016;47:418-25.

20 Bertelmann T, Schulze S. Long-term follow-up of patient with diabetic macular edema receiving fluocinolone acetonide intravitreal implant. Ophthalmol Ther 2015;4:51-8.

21 Elaraoud I, Andreatta W, Kidess A, et al. Use of fluocinolone acetonide for patients with diabetic macular oedema: patient selection criteria and early outcomes in real world setting. BMC Ophthalmol 2016;16:3.

22 Schmit-Eilenberger VK. A novel intravitreal fluocinolone acetonide implant (Iluvien ${ }^{\circledR}$ ) in the treatment of patients with chronic diabetic macular edema that is insufficiently responsive to other medical treatment options: a case series. Clin Ophthalmol 2015;9:801-11.

23 Cunha-Vaz J, Ashton P, lezzi R, et al. Sustained delivery fluocinolone acetonide vitreous implants: long-term benefit in patients with chronic diabetic macular edema. Ophthalmology 2014;121:1892-903 